HortSCIENCE 26(11):1406-1409. 1991.

\title{
Ectomycorrhizae and Drought Acclimation Influence Water Relations and Growth of Loblolly Pine
}

\author{
Sven E. Svenson,' Fred T. Davies, Jr., ${ }^{2}$ and Calvin E. Meier ${ }^{3}$ \\ Department of Horticultural Sciences, Texas A\&M University, College \\ Station, TX 77843
}

Additional index words Pinus taeda, Pisolithus tinctorius, gas exchange

\begin{abstract}
The influence of ectomycorrhizae on drought acclimation was studied in an open-pollinated family of loblolly pine (Pinus taeda $\mathbf{L}$.). Seedlings inoculated with $\mathrm{Pi}$ solithus tinctorius (Pers.) Coker and Couch (Pt) maintained a higher shoot relative growth rate under high and low soil moisture regimes. However, fascicle area, shoot and root mass, and fascicle nutrient elemental content were similar for seedlings inoculated with Pt and noninoculated seedlings. Seedlings under low soil moisture were drought-acclimated by five 11-day drought cycles. During peak water deficit (cycle 6), drought-acclimated, Pt-inoculated seedlings had the lowest predawn fascicle water potential ( $\psi$ pd), conserved water with lowest bulk fascicle diffusive conductance (g), and maintained low $\mathrm{g}$ and transpiration (E) during recovery (cycle 6). Enhanced drought acclimation of Pt-inoculated seedlings was independent of plant size and fascicle nutrient content.
\end{abstract}

The most important commercial pine species in Texas and the southeastern United States is loblolly pine. Careful selection of drought-resistant families (van Buijtenen et al., 1976; Wells, 1983) and ectomycorrhizal symbionts (Marx et al., 1988) has enhanced growth under optimal and suboptimal growing conditions. While the physiological responses of genetically different seedlings to water deficits have been studied (Bongarten and Teskey, 1986; Seiler and Johnson, 1988), the influence of ectomycorrhizae on drought acclimation of loblolly pine of equal size and

Received for publication 13 Nov. 1990. Journal Series no. 25933 of the Texas Agricultural Experiment Station, Texas A\&M Univ., College Station. The technical assistance of S.A. Duray is greatly acknowledged, as well as discussions with R.J. Newton and his critique of the research. The Texas Forest Service provided seeds. The cost of publishing this paper was defrayed in part by the payment of page charges. Under postal regulations, this paper therefore must be hereby marked advertisement solely to indicate this fact.

'Assistant Profess\&. Present address: Univ. of Florida, Agr. Research and Education Center, Fort Lauderdale. FL 33314.

${ }^{2}$ Professor.

${ }^{3}$ Assistant Professor, Dept. of Forest Service. under nonlimiting tissue elemental concentration has not been reported.

Ectomycorrhizal colonization tends to increase plant size (Reid et al., 1983; Sands and Theodorou, 1978) and improve plant nutrition (South et al., 1988); it also has been used to explain growth and drought responses of ectomycorrhizal pine seedlings. Therefore, the objective of this research was to study the influence of inoculation with Pisolithus tinctorius $(\mathrm{Pt})$ on drought acclimation of seedlings of loblolly pine of comparable size and nutritional status.

Surface-sterilized $\left(30 \% \quad \mathrm{H}_{2} \mathrm{O}_{2}\right.$ for $\left.30 \mathrm{~min}\right)$ and stratified (4C for 6 weeks) seeds of an open-pollinated provenance (Texas Forest Service 174/176) were sown in OS-liter RootMaster container books (JPA, West Chicago, Ill.) filled with a medium of 9 silt loam soil : 1 vermiculite $(\mathrm{v} / \mathrm{v})$. Seedlings were grown in a glasshouse under maximum photosynthetic photon flux (PPF) at plant height of $800 \mu \mathrm{mol} \cdot \mathrm{m}^{-2} \cdot \mathrm{s}^{-1}$ (measured with a LI-COR quantum sensor model 1600; LICOR, Lincoln, Neb.) consisting of natural light and incandescent light with 16-h days. Day maxima/night minima averaged 32/25 ( $\pm 2.0 \mathrm{C})$. Seedlings received liquid fertilizer (20N-8.7P-16.6K, Peters 20-20-20; W.R. 
Table 1. Comparison of height $(\mathrm{H})$ and root collar diameter (D), shoot relative growth rate (SRGR), root and shoot dry weight, fascicle surface area, shoot : root ratio, and fascicle area ratio of seedlings of loblolly pine as influenced by soil moisture regime and Pisolithus tinctorius (Pt) inoculation. Measurements were made at the experiment's termination. Means and standard errors, $\mathrm{n}=12$.

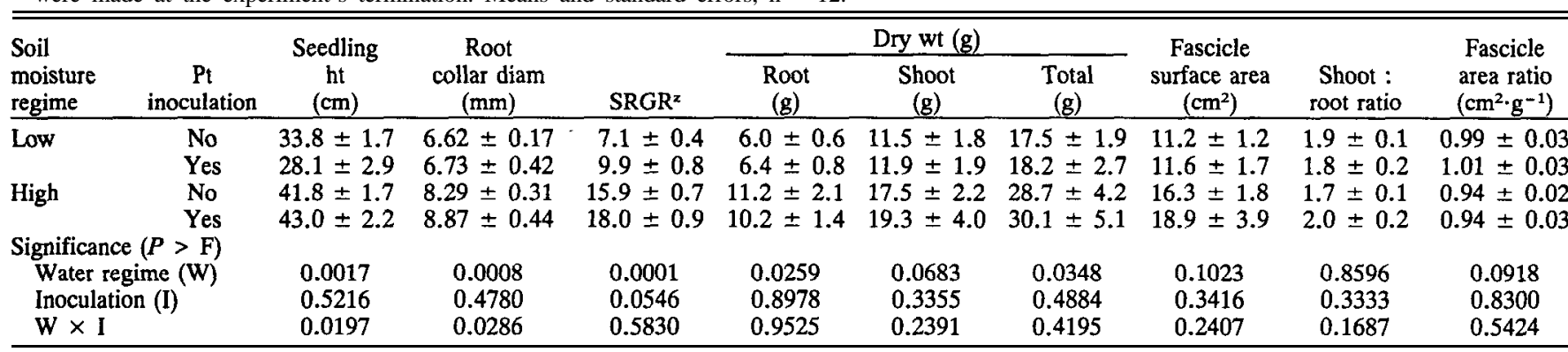

${ }^{2}$ Computed as $\log$ of initial $\mathrm{D}^{2} \mathrm{H}-\log$ of final $\mathrm{D}^{2} \mathrm{H} /$ number of days. Regression of final $\log \mathrm{D}^{2} \mathrm{H}$ (independent variable) with shoot dry weight and total dry weight yielded an $r^{2}$ of 0.92 and 0.85 , respectively.

Table 2. Estimated percent colonization of lateral roots of loblolly pine seedlings as influenced by water deficits and Pisolithus tinctorius (Pt) inoculation, measured at experiment termination. Means and standard errors, $\mathrm{n}=3$.

\begin{tabular}{|c|c|c|c|}
\hline $\begin{array}{l}\text { Soil } \\
\text { moisture } \\
\text { regime } \\
\end{array}$ & $\begin{array}{c}\mathrm{Pt} \\
\text { inoculation }^{\mathrm{z}}\end{array}$ & $\begin{array}{c}\text { Total } \\
\text { ectomycorrhizal } \\
\text { development } \\
(\%) \\
\end{array}$ & $\begin{array}{c}\mathrm{Pt} \\
\text { colonization } \\
(\%)\end{array}$ \\
\hline Low & $\begin{array}{l}\text { No } \\
\text { Yes }\end{array}$ & $\begin{array}{l}26 \pm 6 \\
44 \pm 9\end{array}$ & $\begin{array}{l}15 \pm 7 \\
19 \pm 5\end{array}$ \\
\hline High & $\begin{array}{l}\text { No } \\
\text { Yes }\end{array}$ & $\begin{array}{l}27 \pm 7 \\
48 \pm 7\end{array}$ & $\begin{array}{r}8 \pm 4 \\
15 \pm 1\end{array}$ \\
\hline \multicolumn{4}{|l|}{ Significance $(P>F)^{y}$} \\
\hline Water regime (W) & & 0.6350 & 0.2813 \\
\hline Inoculation (I) & & 0.0404 & 0.1521 \\
\hline $\mathrm{W} \times \mathrm{I}$ & & 0.6928 & 0.5242 \\
\hline
\end{tabular}

${ }^{z}$ Analysis of mycorrhizal roots and fruiting bodies indicated that the primary contaminating species was Thelephora terrestris (Erhr.) Fr.

y Analysis of variance on arcsin-transformed data.

Grace/Sierra, Fogelsville, Pa.) once weekly at $200 \mathrm{mg} \mathrm{N} /$ liter. Between fertilizations, seedlings were watered as needed with distilled water. After 28 weeks, seedlings were transplanted into 1-liter Marx X Rootrainers (Spencer Lemaire, Edmonton, Alberta, Canada) and grown for 6 weeks before drought acclimation regimes were applied. At transplanting, containers were band-inoculated with $50 \mathrm{ml}[1: 20(\mathrm{v} / \mathrm{v})]$ of vegetative mycelium of Pt. Noninoculated seedlings received 50 $\mathrm{ml}$ of autoclaved inoculum to equalize the background microflora in all treatments. Three weeks after transplanting and upon initiation of drought acclimation regimes, seedling height $(\mathrm{H})$ and root collar diameter (D) were recorded for determination of estimated shoot relative growth rate.

Two soil moisture regimes were established based on predawn water potential ( $\Psi$ pd) of fascicles from seedlings from each water regime $\mathrm{x} P \mathrm{Pt}$ inoculation treatment: 1) highsoil-moisture seedlings were watered daily to container capacity, maintaining a $\Psi$ pd of -0.5 $\pm 0.1 \mathrm{MPa}$, as measured with a pressure chamber (Soilmoisture Equipment Corp., Santa Barbara, Calif.) according to Scholander et al. (1965), with precautions taken to avoid resin errors, and 2) low-soil-moisture seedlings were drought acclimated over five cycles lasting 11 days each, after which seedlings were rehydrated to container capacity and a new cycle begun when $\psi$ pd of four sampled seedlings within all treatments averaged $-1.7 \pm 0.2 \mathrm{MPa}$. Drought-acclimated \pm Pt-inoculated seedlings were ex- posed to a peak water deficit (last day of cycle 6) and an 18-h recovery period; comparisons were made with high-soil-moisture seedlings that never experienced drought.

On the first day of cycle 6 , the most recently expanded fascicles from six seedlings for each Pt treatment were sampled for analysis of percent $\mathrm{P}, \mathrm{K}, \mathrm{Ca}, \mathrm{Mg}, \mathrm{Na}$, and (in $\mu \mathrm{g} \cdot \mathrm{g}^{-1}$ ) $\mathrm{Mn}, \mathrm{Fe}$, and $\mathrm{Zn}$. Ashed samples were analyzed on an inductively coupled plasma emission spectrophotometer (model 3510 ICP; Applied Research Laboratories, Dearborn, Mich.).

On the last day of the sixth drought cycle (peak water deficit) and on the following day during recovery $(18 \mathrm{~h}$ after rewatering pots to container capacity), the following features were measured: midday bulk fascicle conductance $(\mathrm{g})$, transpiration (E), $\Psi$ pd, midday fascicle water potential ( $\Psi$ md), osmotic potential $(\psi \pi)$, and turgor pressure $(\psi \pi)$. All measurements were made twice on most recently expanded intact fascicles (at least 12 $\mathrm{cm}$ long) of four seedlings from each water regime $\mathrm{x}$ Pt inoculation combination. A LICOR 1600 steady state porometer was used to measure $\mathrm{g}$ and $\mathrm{E}$, and the location on the fascicle was marked for repeated measurements. Measured $g$ and $\mathrm{E}$ values were corrected for surface area (Svenson and Davies, 1991).

On the same seedlings used for $\psi$ pd measurements, $\psi$ md was measured, and then the fascicles were placed in air-tight vials and frozen in liquid nitrogen for later measurement of $\psi \pi$ on frozen-thawed tissue using a
Wescor C-52 chamber in conjunction with a Wescor HR33T dewpoint hygrometer (Wescor, Logan, Utah) according to Turner (1981). Calculation of $\psi \rho$ was the difference between $\psi$ md and $\psi \pi$.

Environmental conditions during measurements on the day of peak stress were: ambient air, $28.2 \pm 0.9 \mathrm{C}$; relative humidity, $66.7 \% \pm 0.4 \%$; and PPF, $382 \pm 17$ $\mu \mathrm{mol} \cdot \mathrm{m}^{-2} \cdot \mathrm{s}^{-1}$, measured with a LI-COR 1600. Midday environmental conditions during recovery were: ambient air, $28.3 \pm 0.6 \mathrm{C}$; relative humidity, $66.4 \% \pm 0.8 \%$; and $\mathrm{PPF}$, $392 \pm 13 \mu \mathrm{mol} \cdot \mathrm{m}^{-2} \cdot \mathrm{s}^{-1}$.

Final seedling $\mathrm{H}$ and $\mathrm{D}$ were recorded. Using corresponding pretreatment measurements, shoot relative growth rate (SRGR) was estimated as the $\log$ of final $D^{\mathrm{z}} \mathrm{H}-\log$ of initial $D^{2} \mathrm{H} /$ number of days. Log $\mathrm{D}^{2} \mathrm{H}$ was shown to be an excellent indicator of loblolly pine shoot dry weight responses to fertilizer or ectomycorrhizal treatments (Hatchell et al., 1985). Seedlings were harvested; foliar, shoot, root, and total plant dry mass were recorded; and shoot : root ratios were calculated. Total fascicle surface area (TSA) was estimated using dry-mass regression methods (Ohmart and Thomas, 1986), and fascicle area ratio (LAR) $\left(\mathrm{cm}^{2} \cdot \mathrm{g}^{-1}\right.$ shoot mass) was calculated. The percentage of lateral roots colonized by Pt or by other ectomycorrhizal fungi was estimated visually (Ruehle and Wells, 1984).

Water relations indicators and nutritional data were analyzed using a water regime $x$ $\mathrm{Pt}$ inoculation factorial treatment arrangement in a completely randomized design, using four replications and two nested subsamples. Harvest data were similarly analyzed using 12 replications. Above data were analyzed with SAS General Linear Models using Type III sums of squares (SAS Institute, Cary, N.C.). Colonization data were tested using analysis of variance after an arcsin transformation of the data (Little and Hills, 1978).

Seedlings inoculated with Pt were shorter and thinner than noninoculated seedlings 3 weeks before initiation of water regimes, but all seedlings had similar $\mathrm{H}$ and D upon initiation of water regimes (data not shown). Pt-inoculated seedlings were most likely growing at a faster rate for $\mathrm{H}$ and $\mathrm{D}$ to be similar among treatments upon initiation of water regimes. Temporary growth reductions following mycorrhizal colonization have 
Table 3. Comparison of predawn fascicle water potential ( $\psi$ pd) and midday fascicle water potential ( $\psi$ md), osmotic potential $(\psi \pi)$, turgor pressure $(\psi \rho)$, conductance $(\mathrm{g})$, and transpiration (E) at peak water deficit and after recovery of seedlings of loblolly pine as influenced by water deficits and Pisolithus tinctorius (Pt) inoculation. Means and standard errors, $\mathrm{n}=8$.

\begin{tabular}{|c|c|c|c|c|c|c|c|c|}
\hline \multirow{2}{*}{$\begin{array}{l}\text { Day of } \\
\text { measurement }\end{array}$} & \multirow{2}{*}{$\begin{array}{l}\text { Soil } \\
\text { moisture } \\
\text { regime }\end{array}$} & \multirow{2}{*}{$\begin{array}{c}\mathrm{Pt} \\
\text { inoculation }\end{array}$} & $\psi p d$ & $\psi \mathrm{md}$ & $\psi \pi$ & $\psi \rho$ & g & $\mathrm{E}$ \\
\hline & & & \multicolumn{4}{|c|}{ (MPa) } & \multicolumn{2}{|c|}{$\left(\mathrm{mmol} \cdot \mathrm{m}^{-2} \cdot \mathrm{s}^{-1}\right)$} \\
\hline \multirow{4}{*}{$\begin{array}{l}\text { Peak water } \\
\text { deficit }\end{array}$} & Low & No & $-1.20 \pm 0.05$ & $-1.79 \pm 0.04$ & $-2.07 \pm 0.07$ & $0.28 \pm 0.09$ & $0.144 \pm 0.002$ & $0.47 \pm 0.04$ \\
\hline & & Yes & $-1.34 \pm 0.08$ & $-1.81 \pm 0.04$ & $-2.09 \pm 0.09$ & $0.28 \pm 0.07$ & $0.108 \pm 0.005$ & $0.39 \pm 0.06$ \\
\hline & High & No & $-0.53 \pm 0.02$ & $-0.95 \pm 0.09$ & $-2.01 \pm 0.13$ & $1.06 \pm 0.07$ & $0.547 \pm 0.011$ & $1.63 \pm 0.06$ \\
\hline & & Yes & $-0.54 \pm 0.02$ & $-0.88 \pm 0.04$ & $-1.72 \pm 0.06$ & $0.84 \pm 0.09$ & $0.614 \pm 0.012$ & $1.78 \pm 0.13$ \\
\hline \multirow[t]{4}{*}{ Recovery } & Low & No & $-0.92 \pm 0.02$ & $-0.97 \pm 0.09$ & $-1.98 \pm 0.05$ & $1.01 \pm 0.08$ & $0.353 \pm 0.003$ & $0.82 \pm 0.06$ \\
\hline & & Yes & $-0.88 \pm 0.03$ & $-0.91 \pm 0.07$ & $-2.05 \pm 0.06$ & $1.14 \pm 0.07$ & $0.270 \pm 0.003$ & $0.68 \pm 0.03$ \\
\hline & High & No & $-0.48 \pm 0.01$ & $-0.74 \pm 0.07$ & $-1.74 \pm 0.06$ & $1.00 \pm 0.06$ & $0.614 \pm 0.004$ & $1.40 \pm 0.08$ \\
\hline & & Yes & $-0.48 \pm 0.01$ & $-0.84 \pm 0.11$ & $-1.77 \pm 0.10$ & $0.93 \pm 0.06$ & $0.700 \pm 0.005$ & $1.64 \pm 0.21$ \\
\hline \multicolumn{9}{|c|}{ Significance $(P>$ F) } \\
\hline \multicolumn{9}{|c|}{ Peak water deficit } \\
\hline \multicolumn{2}{|c|}{ Water regime $(\mathrm{W})$} & & 0.0057 & 0.0015 & 0.0066 & 0.0239 & 0.0121 & 0.0001 \\
\hline \multicolumn{2}{|c|}{ Inoculation (I) } & & 0.1310 & 0.2844 & 0.5273 & 0.3913 & 0.2602 & 0.7630 \\
\hline$W \times I$ & & & 0.0376 & 0.0653 & 0.0659 & 0.0021 & 0.0048 & 0.1205 \\
\hline \multicolumn{9}{|l|}{ Recovery } \\
\hline \multicolumn{2}{|l|}{ W } & & 0.0003 & 0.0584 & 0.0517 & 0.3002 & 0.0108 & 0.0188 \\
\hline \multicolumn{2}{|l|}{ I } & & 0.5004 & 0.7863 & 0.6320 & 0.5083 & 0.1572 & 0.7877 \\
\hline \multicolumn{2}{|l|}{$W \times I$} & & 0.3533 & 0.0439 & 0.5987 & 0.0619 & 0.0184 & 0.0483 \\
\hline
\end{tabular}

been previously reported (Smith and Gianinazzi-Pearson, 1988).

Drought acclimation reduced seedling $\mathrm{H}$, D, SRGR, and root, shoot, and total plant dry weights (Table 1). Shoot : root ratios, LAR, and fascicle surface area (FSA) were not significantly influenced by water regime. Pt-inoculated seedlings had a higher SRGR than noninoculated plants within high and low soil moisture regimes, although size and surface area characteristics were similar (Table 1). The difference in SRGR was not related to plant size but to the faster growth rates of Pt-inoculated seedlings before initiation of drought acclimation treatments. Our treatments were conducted during a growth period in which $\pm \mathrm{Pt}$-inoculated plants were of equal size, which was an objective of this research. There were no significant differences between Pt-inoculated and noninoculated seedlings for the tissue concentrations of any of the minerals checked (data not shown).

Inoculation with Pt increased overall colonization of lateral roots (Table 2). Some natural colonization by $\mathrm{Pt}$ and other ectomycorrhizae occurred on noninoculated seedlings. Natural colonization of loblolly pine occurs when seedlings are outplanted (Marx et al., 1985; South et al., 1988), and its prevention is naturally anomalous. Plant responses to low levels of Pt colonization and small differences in the percentage of Pt colonization have been reported (Dixon et al., 1981). Water regime did not influence colonization (Table 2).

Response of $\psi \mathrm{pd}, \psi \pi, \mathrm{g}$, and $\mathrm{E}$ to Pt inoculation differed for the high and low soil moisture regimes (Table 3), even though inoculation did not significantly increase $\mathrm{Pt}$ colonization (Table 2). Responses to Pt inoculation may have been induced by 1) the nonsignificant increase in Pt colonization, 2) the increase in total ectomycorrhizal development, or 3) the host-plant response to an interaction between $\mathrm{Pt}$ and other colonizing ectomycorrhizal fungi and associated microflora. The first and third explanations may be more appropriate since responses to increasing total ectomycorrhizal development are characteristically associated with increasing $\mathrm{P}$ nutrition (South et al., 1988), which did not occur in our experiment.

At peak water deficit (last day of cycle 6), seedlings in the low soil moisture regime had reduced $\psi \mathrm{pd}, \psi \mathrm{md}, \psi \pi, \psi \mathrm{p}, \mathrm{g}$, and $\mathrm{E}$ compared to the nonstressed plants in the high soil moisture regime, regardless of $\mathrm{Pt}$ inoculation (Table 3). A similar response continued $18 \mathrm{~h}$ after all plants were irrigated, indicating that acclimation to drought had occurred. Bongarten and Teskey (1986) noted a similar drought-induced acclimation of $\mathrm{g}$ but did not determine ectomycorrhizal colonization.

High-soil-moisture plants inoculated with Pt tended to have lower $\psi \mathrm{p}$ and higher $\mathrm{g}$ and E than noninoculated seedlings (Table 3). During peak water deficit, those drought acclimated and inoculated with Pt had lower $\psi$ pd and g than noninoculated seedlings, and during recovery $\mathrm{g}$ and $\mathrm{E}$ remained lower. Using $\psi$ pd as an indicator of container-soil bulk water potential (Rudich et al., 1981), Pt-inoculated seedlings experienced a greater peak soil water deficit than noninoculated seedlings (Table 3), which may explain their greater acclimation (i.e., reduced g). In contrast, plants inoculated with Pt and held moist were not conserving water, as indicated by higher $\mathrm{g}$ and $\mathrm{E}$ compared to noninoculated plants. During nondrought conditions, ectomycorrhizal Douglas fir [Pseudotsuga menziesii (Mirb.) France] seedlings characteristically have higher $\mathrm{g}$ than noninoculated plants (Parke et al., 1983). Hence, when water becomes limiting in a containerized system, the higher $\mathrm{g}$ of nonacclimated ectomycorrhizal plants of Douglas fir resulted in dessication and lower $\psi$ pd and reduced $\mathrm{g}$, as with Pt-inoculated seedlings of loblolly pine in our experiment.

Decreased $g$ after acclimation of Pt-inoculated seedlings would theoretically slow consumption of available container water. Hyphal and rhizomorph growth may enhance water absorption when water is easily available (Sands and Theodorou, 1978). The lower $\psi$ pd of acclimated Pt-inoculated seedlings observed at peak stress in our experiment (Table 3) suggested that increasing ectomycorrhizal development may limit total available water in containerized systems.

Decreased g in Pt-inoculated seedlings may be at the expense of photosynthetic rates, as shown by the linear relationship between photosynthesis and $\mathrm{g}$ in loblolly pine (Teskey et al., 1986). In contrast, Seiler and Johnson (1988) found that photosynthesis was maintained at lower rates of $\mathrm{g}$ in droughtacclimated loblolly pine, increasing wateruse efficiency (they did not determine ectomycorrhizae or $\mathrm{Pt}$ influence). SRGR was higher in acclimated Pt-inoculated seedlings of loblolly pine during water deficits (Table 1), suggesting that reduced $\mathrm{g}$ in Pt-inoculated seedlings was not limiting photosynthesis or growth. The combination of higher SRGR and lower g suggests that Pt-inoculated seedlings were more acclimiated to drought. The higher SRGR of Pt-inoculated seedlings during periods when water availability is reduced may explain the greater survival and growth of outplanted Pt-inoculated seedlings on optimal growing sites (Marx et al., 1988).

Physiological responses of ectomycorrhizal conifer seedlings to drought have been confounded by larger evaporative surface and plant size differences (Parke et al., 1983; Sands and Theodorou, 1978) and/or higher $\mathrm{P}$ in tissue of inoculated vs. noninoculated plants (Reid et al., 1983; South et al., 1988). Our study demonstrated that enhanced drought acclimation of loblolly pine seedlings by $\mathrm{Pt}$ inoculation was independent of plant size and foliar nutrient concentration.

\section{Literature Cited}

Bongarten, B.C. and R.O. Teskey. 1986. Water relations of loblolly pine seedlings from diverse geographic origins. Tree Physiol. 1:265-276.

Dixon, R.K., H.E. Garrett, and G.S. Cox. 1981.

Container- and nursery-grown black oak seed- 
lings inoculated with Pisolithus tinctorius: Growth and ectomycorrhizal development following outplanting on an Ozark clear-cut. Can. J. Forest Res. 11:492-496.

Hatchell, G.E., C.R. Berry, and H.D. Muse. 1985. Nondestructive indices. related to above ground biomass of young loblolly and sand pines on ectomycorrhizal and fertilizer plots. Forest Sci. 31:419-427.

Little, T.M. and F.J. Hills. 1978. Agricultural experimentation. Wiley, New York.

Marx, D.H., C.E. Cordell, and A. Clark, III. 1988. Eight year performance of loblolly pine with Pisolithus ectomycorrhizae on a good-quality forest site. Southern J. Appl. For. 12:275-280.

Marx, D.H., A. Hedin, and S.F.P. Poe, IV. 1985. Field performance of Pinus caribaea var. Hondurensis seedlings with specific ectomycorrhizae and fertilizer after three years on a savanna site in Liberia. For. Ecol. Mgt. 13:1-25.

Ohmart, C.P. and T.R. Thomas. 1986. Estimating surface area of Pinus radiata needles using dry weight. Austral. For. Res. 16:85-89.

Parke, J.L., R.G. Lindennan, and C.H. Black. 1983. The role of ectomycorrhizas in drought tolerance of douglas fir seedlings. New Phytol. 95:83-95.

Reid, C.P.P., F.A. Kidd, and S.A. Ekwebelam. 1983. Nitrogen nutrition, photosynthesis and carbon allocation in ectomycorrhizal pine. Plant Soil 71:415-432.

Rudich, J., E. Rendon-Poblete, MA. Stevens, and A.I. Ambri. 1981. Use of leaf water potential to determine water stress in field-grown tomato plants. J. Amer. Soc. Hort. Sci. 106:732-736.

Ruehle, J.L. and C.G. Wells. 1984. Development of Pisolithus tinctorius ectomycorrhizae on container grown pine seedlings as affected by fertility. Forest Sci. 30:1010-1016.

Sands, R. and C. Theodorou. 1978. Water uptake by mycorrhizal roots of radiata pine seedlings. Austral. J. Plant Physiol. 5:301-309.

Scholander, P.F., H.T. Hammel, E.D. Bradstreet, and E.A. Hemmingsen. 1965. Sap pressure in vascular plants. Science 148:339-346.

Seiler, J.R. and J.D. Johnson. 1988. Physiological and morphological responses of three halfsib families of loblolly pine to water-stress conditioning. Forest Sci. 34:487-495.

Smith, S.E. and V. Gianinazzi-Pearson. 1988. Physiological interactions between symbionts in vescicular-arbuscular mycorrhizal plants. Annu. Rev. Plant Physiol. Plant Mol. Biol. 39:221244.

South, D.B., R.J. Mitchell, R.K. Dixon, and M. Vedder. 1988. New ground syndrome: An ectomycorrhizal deficiency in pine nurseries. Southern J. Applied For. 12:234-239.

Svenson, S.E. and F.T. Davies, Jr. 1991. Estimating surface area of segments of intact nine fascicles under water stress for gas exchange analysis. Tree Physiol. (In press.)

Teskey, R.O., J.A. Fites; L.J. Samuelson, and B.C. Bongarten. 1986. Stomatal and nonstomatal limitations to net photosynthesis in Pinus taeda L. under different environmental conditions. Tree Physiol. 2:131-142.

Turner, N.C. 1981. Techniques and experimental approaches for the measurement of plant water status. Plant Soil 58:339-366.

van Buijtenen, J.P., M.V. Bilan, and R.H. Zimmerman. 1976. Morphophysiological characteristics related to drought resistance in Pinus taeda L., p. 349-359. In: M.G.R. Connell and F.T. Last (eds.). Tree physiology and yield improvement. Academic, New York.

Wells, 0.0. 1983. Southwide pine seed source study-Loblolly pine at 25 years. Southern J. Applied For. 7:63-70. 